DEPARTMENT OF THE INTERIOR

U.S. GEOLOGICAL SURVEY

\title{
A VAX and MS-DOS Computer Program Package for Depth Conversion of Digitized, Line-drawing Interpretations of Seismic Sections
}

\author{
By John J. Miller ${ }^{1}$
}

Open-File Report 91-303A

Although this program package has been used by the U.S. Geological Survey, no warranty, expressed or implied, is made by the USGS as to the accuracy and functioning of the programs and related program material, nor shall the fact of distribution consitute any such warranty, and no responsibility is assumed by the USGS in connection therewith.

This report is preliminary and has not been reviewed for conformity with U.S. Geological Survey editorial standards and stratigraphic nomenclature. Any use of trade names is for descriptive purposes only and does not imply endorsement by the U.S. Geological Survey.

1 U.S. Geological Survey, Box 25046, Denver Federal Center, Denver, CO 80225 


\section{CONTENTS}

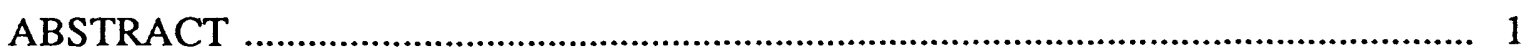

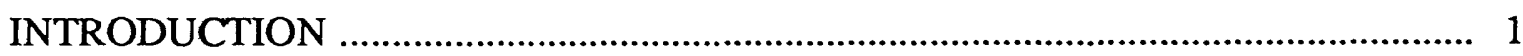

SOFTWARE/HARDWARE REQUIREMENTS AND AVAILABILITY ...................... 3

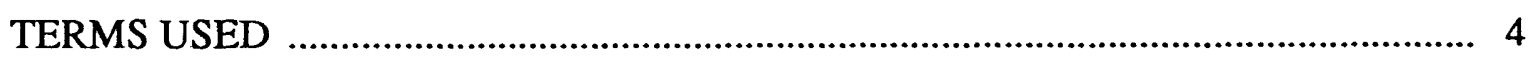

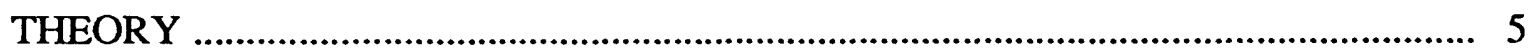

Seismic Reflection Surveys .............................................................................. 5

Depth Conversion of Seismic Sections ........................................................................ 6

PROGRAM NAMES, FUNCTION, AND COMPATIBILITY .................................... 12

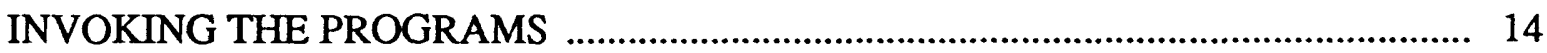

Menu Control ............................................................................................ 14

Executing the Programs Separately ...................................................................... 15

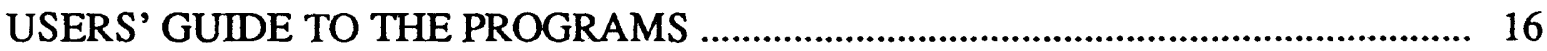

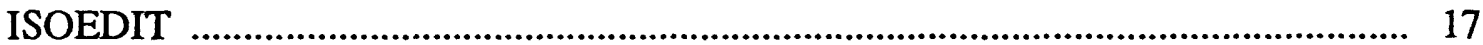

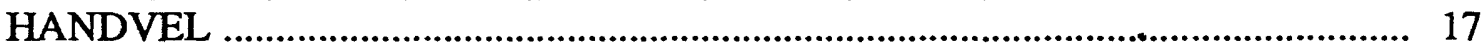

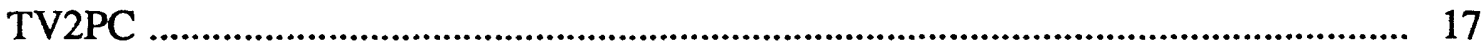

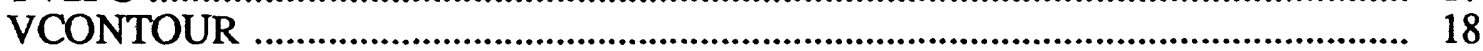

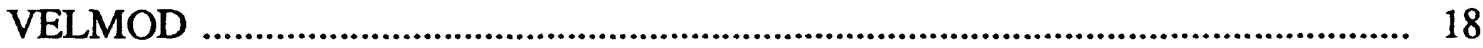

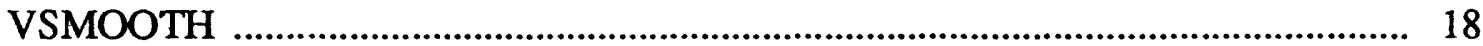

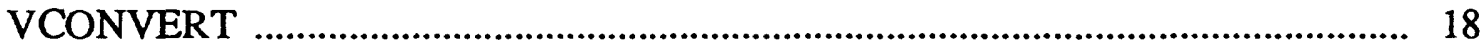

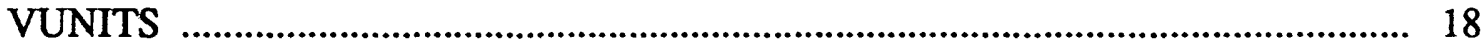

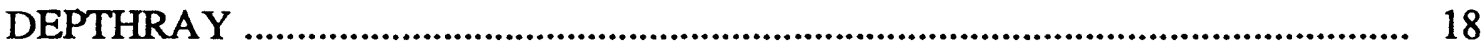

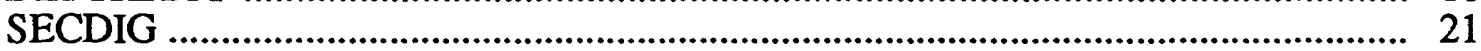

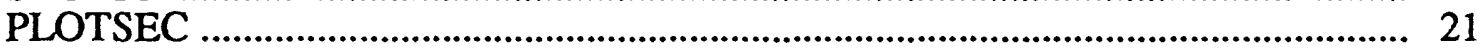

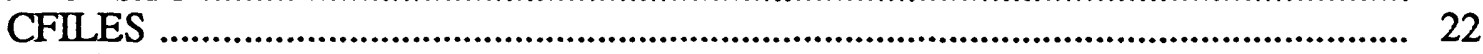

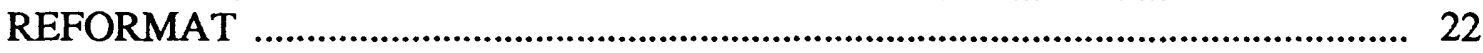

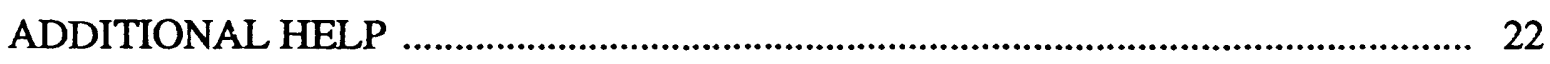

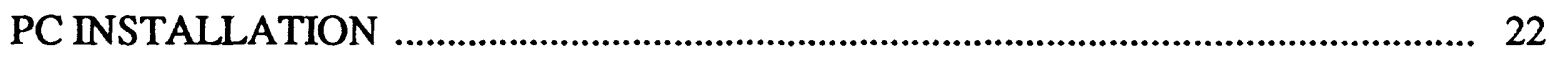

APPENDIX …

The Velocity Files Format ..................................................................................... 23

The Digitized Seismic Section Format .......................................................................... 24

The Raypath File Format ................................................................................................ 24

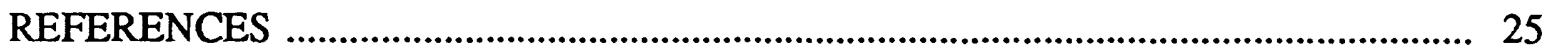




\section{ILLUSTRATIONS}

1. Example of a processed seismic record section. ...................................................... 5

2. Stacked seismic traces in time (left) and depth. .................................................... 7

3. Line-drawing interpretation, digitized using SECDIG. ….......................................... 8

4. Image ray, traced downward from location 20 (Figure 3). ......................................... 9

5. Image rays traced at odd-numbered surface locations. .............................................. 9

6. Depth section, created from image ray tracing (Figure 5) ........................................... 10

7. Depth section created using vertical stretching method. .............................................. 10

8. Portions of Figures 6 and 7 at expanded scale. ...................................................... 11

9. VAX menu screen for program VELPACK. ............................................................ 14

10. PC menu screen for program VELPACK. ..................................................... 15

11. Parameter selection screen for program DEPTHRAY. ............................................ 17

12. Image rays, using RMS velocities from file VELRMS.LIS ……............................. 19

12. Depth section created from rays shown in Figure 12. .......................................... 20

14. Depth section using vertical stretching and RMS vels. .......................................... 21

\section{TABLES}

1. Program Names, Functions, and Computer Availability …....................................... 12

2. Sequence of steps used to create a seismic depth section. ......................................... 13 


\title{
A VAX and MS-DOS Computer Program Package for Depth Conversion of Digitized, Line-drawing Interpretations of Seismic Sections \\ By John J. Miller
}

\begin{abstract}
A new computer program package is available for use on both the VAX minicomputer and the PC-type (MS-DOS operating system) microcomputer to create digitized, line-drawing interpretations from seismic sections, to transform the interpretation from a time-section to a depth-section by means of ray-tracing techniques (vertical- or image-ray), and to modify the velocity models used for the depth transformation in various ways. The required input and output files are 100\% compatible between the VAX and the PC and utility programs exist to prepare velocity models for transfer between computers. The line-drawing interpretations (in time or depth) can be displayed on the PC screen in CGA, EGA, VGA, or Hercules resolution, or as a hardcopy via an electrostatic plotter attached to the VAX. The VAX programs can access the DISCO seismic data processing system's database and thereby modify velocity models for further processing in ways not available through DISCO. Each program can be executed individually, or by means of a menu-controlled user interface which provides access to all of the programs.
\end{abstract}

The source code for both the PC and VAX versions of each program is provided. With few changes, the PC source code can be transported to most computers and the VAX source code can be transported to any computer that has proprietary DISCO software installed.

\section{INTRODUCTION}

Reflection seismic data are recorded and processed using two-way-travel-time (TWTT, the time it takes seismic energy to travel from the energy source to a reflector, and back to the source) as the Z, or depth, coordinate (Figure 1). However, after processing, it is usually necessary to transform the time axis to depth in order to properly interpret the geometric configuration of the geologic structure. Depth conversion requires subsurface velocities, but usually, the velocities used in processing the seismic data must be modified a number of times before an acceptable time-to-depth transformation is achieved.

Converting seismic traces to depth and displaying the result is a time-consuming, iterative process, which is compounded each time the velocity model is modified. Also, the interpreter may have access to only the processed seismic section (on paper, mylar, etc.) and thus cannot perform depth conversion on the individual traces. However, using a copy of the section, the reflectors of interest can be digitized as a "line-drawing interpretation" which can be converted to depth in a few minutes using the programs contained in this package. The depth conversion process can be carried out using any number of different velocity models, in an iterative fashion, until an acceptable depth configuration is achieved.

The digitized interpretation can be extremely complex, consisting of an unlimited number of interpreted horizons. These "horizons" can be reflectors, fault planes, or other features inferred from the seismic data (e.g. unconformities or faults that do not manifest themselves as distinct reflections). Velocities used for the depth conversion can be provided when digitizing the time section or can be contained in a separate velocity file which can then be modified as needed using the velocity modification programs contained in this package.

If the digital seismic data are available, the final velocity model can be used to convert the actual seismic data to depth. However, even when the digital data are available, it is sometimes better to show the depth section as a line-drawing only, especially if the seismic waveforms become distorted because of abrupt changes in either the velocity used for depth conversion or in 
the frequency content of the seismic data itself. In such a case, high-quality, Versatec plots can be used to display the digitized sections. The user can control the scale and the frequency of annotation in both the $\mathrm{X}$ and $\mathrm{Y}$ directions for all Versatec displays.

This report describes a series of computer programs, compatible with both the VAX minicomputer and the MS-DOS microcomputer, to create a digitized, line-drawing interpretation from a time-migrated seismic section, to transform the digitized line-drawing from a time-section to a depth-section by means of ray-tracing techniques (vertical- or image-ray), and to modify the velocities used for the depth transformation in various ways. An overview and user's guide for each program is provided. A complete description of the depth conversion program itself is given by Miller (in preparation).

In this report, the term PC (PC-type, PC programs, etc.) is used to mean an IBM-compatible microcomputer running the MS-DOS operating system. The term VAX is used to mean a Digital Equipment Corporation (DEC) VAX minicomputer running the VMS operating system and proprietary DISCO seismic data processing software. The source code for the PC programs is provided (except for program ISOEDIT which is documented separately in Zihlman, 1989) and is transportable to other computers. The VAX source code is also provided and is transportable to other computers having proprietary DISCO software installed. Some hardware-specific changes to the source code may be required (e.g. file-opening syntax). Additional information is given in the section entitled "Software/Hardware Requirements and Availability."

The program package provides the following functions in order to convert a time section to depth:

1. Digitize a line-drawing interpretation of a seismic section.

2. Convert the digitized line-drawing from time to depth using vertical, or image, ray-tracing.

3. Display the time or depth horizons, or the image rays, on the VERSATEC plotter or on the PC-screen.

4. Combine files created in separate runs of digitizing, or depth conversion, into one file.

5. Convert a digitized interpretation created using a version of this software prior to version 1.2 into a version 1.2 -format file.

The velocity modification programs can be used in conjunction with the depth-conversion programs, or independently during the processing and interpreting of the seismic data. For example, RMS velocity values used for stacking may need to be reduced when performing migration, interval velocities may need to be calculated from the RMS velocities in order to estimate rock types, or abrupt changes in stacking velocity may need to be smoothed in order to properly migrate the data (or to convert it from time to depth). The velocity modification programs for the VAX are compatible with the DISCO seismic data processing system's database (called Seisdata) and can thus be used to modify velocities in ways not available through DISCO. The following programs are provided to modify velocities:

1. Smooth velocities in time and space by means of a weighted average technique.

2. Convert RMS-velocity to INTERVAL-velocity, and the reverse.

3. Convert velocity units from $\mathrm{m} / \mathrm{s}$ to $\mathrm{ft} / \mathrm{s}$, and the reverse.

4. Interactively modify isovelocity or $t$ versus $v$ displays on the PC-screen.

5. Change TWTT values to the midpoint of the interval, prior to contouring interval velocities.

6. Extract velocity models from the Seisdata database used by DISCO on the VAX for use on the PC. 
7. Create DISCO *CALL DEFINE (HANDVEL) style card images on the PC for use on the VAX.

\section{SOFTWARE/HARDWARE REQUIREMENTS AND AVAILABILITY}

Program package VELPACK (version 1.2) is designed to create digitized, line-drawing interpretations from time-migrated seismic sections, to transform the interpretation from a timesection to a depth-section by means of ray-tracing techniques (vertical- or image-ray), and to modify the velocity models used for the depth transformation in various ways.

MS-DOS programs: The MS-DOS programs were developed using Microsoft Fortran Version 5.0 and Microsoft Basic Version 7.1 on a Kaypro 286i microcomputer having an Intel$80286 \mathrm{CPU}$, enhanced keyboard, math coprocessor and MS-DOS V3.21 operating system. The programs may be run on PC, XT, and AT type microcomputers using MS-DOS (PC-DOS) V2.0 or greater. The programs will use a math coprocessor if one is available, otherwise they will use software emulation. Those programs that use on-screen graphics (ISOEDIT, PLOTSEC and DEPTHRAY) will automatically detect and use the highest possible video resolution from the following: VGA, EGA, CGA (color or monochrome), or Hercules (monochrome). Graphics capability for DEPTHRAY is optional; its output can be stored in files for display on other computers equipped with graphics capability.

VAX-programs: The VAX programs are designed to be used with proprietary DISCO seismic data processing software and were developed using FORTRAN-77 on a DEC VAX 11/780 minicomputer having an FPS-120B array processor, a VERSATEC electrostatic plotter (22-inch wide, black and white), an HSR-11 rasterizer, and VMS V5.1 operating.system. The programs that modify velocities are compatible with the DISCO seismic data processing system's database, version 6.0 and above. Proprietary subroutines that access the array processor, Calcompequivalent graphics, and Seisdata database were provided by Cogniseis Development Corporation. The array processor is required only for program VSMOOTH; the plotter and rasterizer are used only in programs PLOTSEC and DEPTHRAY. The plotter and rasterizer are optional for DEPTHRAY; its output can be stored in files for display on other computers equipped with such devices.

The required input and output files are in standard ASCII format and are 100\% compatible between the VAX and MS-DOS computers and should be compatible with other hardware that can utilize ASCII-format files. Both the MS-DOS and VAX version of the digitizing program SECDIG, assume a Summagraphics digitizer having either a 13-key cursor pad (gray key, keys $0-9$, \#, and * keys) or 4-key cursor pad $(Z, 1,2$, and 3 keys) and access through the serial port. The source code can be modified and recompiled to accept input from other digitizers.

This open-file report is available in paper copy, OF91-303A. The executable files for the MSDOS programs are available on a diskette, OF91-303B; the source code for both the VAX and MS-DOS programs is available on a diskette, OF91-303C. The source code for the proprietary subroutines mentioned above is not provided; only the calling syntax for those subroutines is included. All diskettes are 5.25 inches and formatted for 1.2 Mbyte capacity. 


\section{TERMS USED}

Horizon - The interface between two layers. This interface can be a reflector, fault plane, unconformity, or any other boundary interpreted from the seismic section. The physical properties (velocity, density, etc.) of the materials on either side of the horizon need not be different.

Interval velocity - Seismic wave velocity measured over a depth interval (Sheriff, 1976). The Dix formula (1955) gives one relationship between interval and RMS velocity. In this report, the velocity of the medium between two horizons (a layer) is the interval velocity.

Layer - The space between two consecutive horizons.

Line-drawing interpretation - All of the digitized horizons as interpreted from a seismic section (usually after time-migration).

RMS velocity - Root-mean-square velocity. This is the velocity measured by stacking velocity analyses based on normal moveout measurement and the assumption of parallel layers (Sheriff, 1976).

Seismic Section - The end result of processing the data recorded on a seismic line. It consists of seismic traces from consecutive surface locations, displayed side-by-side. It is assumed that each trace is the equivalent of a noise-free recording from a coincident source and receiver located at that particular surface location. It may also be called a seismic line, record section, seismic profile, stacked section, final stack, migrated stack, etc. The $\mathrm{X}$ coordinate is distance along the ground surface and the $\mathrm{Y}$ coordinate is depth, measured by TWTT.

Velocity Function - Seismic Velocity expressed as a mathematical function of depth or time (Sheriff, 1976). It is usually represented by a series of time-velocity points beneath a particular surface location.

Velocity Model - A series of velocity functions for a region (Sheriff, 1976). In this paper, velocity model usually means all of the velocity functions for one seismic line. 


\section{THEORY}

\section{Seismic Reflection Surveys}

In a seismic reflection survey, seismic data are recorded by measuring the time elapsed between the energizing of a seismic energy source and the arrival of that energy at a detector array or arrays. The energy source and detectors are usually located at or near the surface of the earth (ground or water surface). The source can be an explosive charge, mechanical vibration or impact, release of compressed air or water, etc. Some of the energy released by the source propagates through the earth as elastic waves and is reflected back toward the surface by changes in the acoustic impedance (the product of density and velocity) of the medium. In modern seismic surveys, a large number of detector arrays (usually 96 or more) are positioned at the surface along the line of the survey, detect the arrival of the reflected energy, and record the signals digitally on magnetic tape. The recorded signals from one source point and its associated detectors are called a record, or shot, and a single seismic profile (sometimes called a seismic line) can consist of many hundreds of records. These data usually require extensive computer processing in order to produce a seismic section suitable for geologic interpretation. Such a seismic section (sometimes called a record section or migrated stack), is shown in Figure 1.

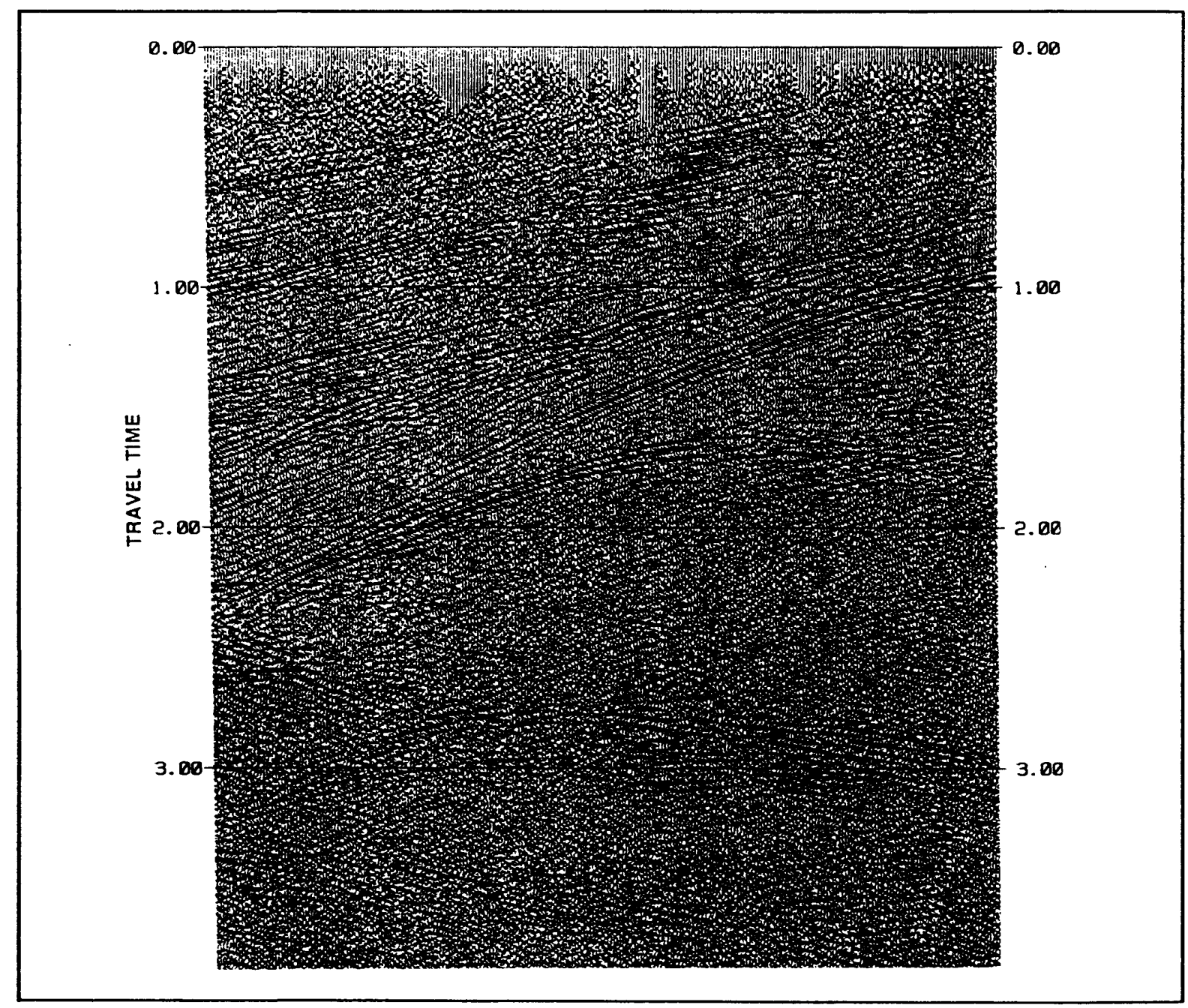

Figure 1. Example of a processed seismic record section. Vertical axis is Two-Way-Travel-Time (TWTT). 


\section{Depth Conversion of Seismic Sections}

The coherent reflectors in Figure 1 are assumed to mimic the subsurface geologic structure. However, the vertical coordinate of Figure 1 is Two-Way Travel Time (TWTT), i.e. the time that it takes the seismic energy to travel from the energy source to the reflector, and back to a detector coincident with the source. The travel times are dependent on the velocity of the medium. In the case of modern, multichannel seismic data, velocities can be estimated from the seismic data itself. Independent velocity information may also be available from nearby boreholes by means of sonic logs, vertical seismic profiles, checkshot surveys, or other methods.

The estimated velocities can be used to calculate a simple time-depth relationship. Figure 2 is a display of two sets of three adjacent traces from a seismic section with vertical coordinates of time (left) and depth (right), respectively. Also shown is the velocity function used for the time-depth transformation. The velocities have been defined at integer increments of 1 second TWTT. The formula that describes the relationship between interval velocity and RMS velocity is given by Dix (1955). The depth distance of each defined interval is that interval's travel time multiplied by its interval velocity divided by 2 (to compensate for twoway travel time). Thus the depth distance between 1 and 2 seconds is 1250: ((2.0 -

$1.0) * 2500) / 2$. The depth distance between 4 and 5 seconds is 2000 , because of that interval's higher velocity.

Note that on the depth-converted traces (Figure 2, right), the apparent frequency content of the data between depths 5150 and 7150 is lower than on the corresponding time representation (Figure 2, left, between 4 and $5 \mathrm{~s}$ ) because the same seismic waveforms take up a proportionally larger part of the trace. The type of depth conversion just described is commonly called "vertical stretching", for obvious reasons.

If the velocities used are reasonably accurate, the vertical stretching method is valid for depth conversion as long as there is no structural dip present. Of course, the absence of dip is rarely the case. A processing step called migration is performed on seismic sections to properly position reflectors on a time section (Clairbout and Doherty, 1972, Claerbout, 1976). However, Hubral (1977) observed that time migration positions a reflector beneath the surface point at which its ray emerges vertically. Thus to properly convert a time-migrated section to depth, rays should be traced downward from each surface location, with the beginning azimuth being vertical to the surface. Each time the ray reaches a dipping interface, it will be deflected laterally based on Snell's law of refraction. Hubral called these rays image rays. 


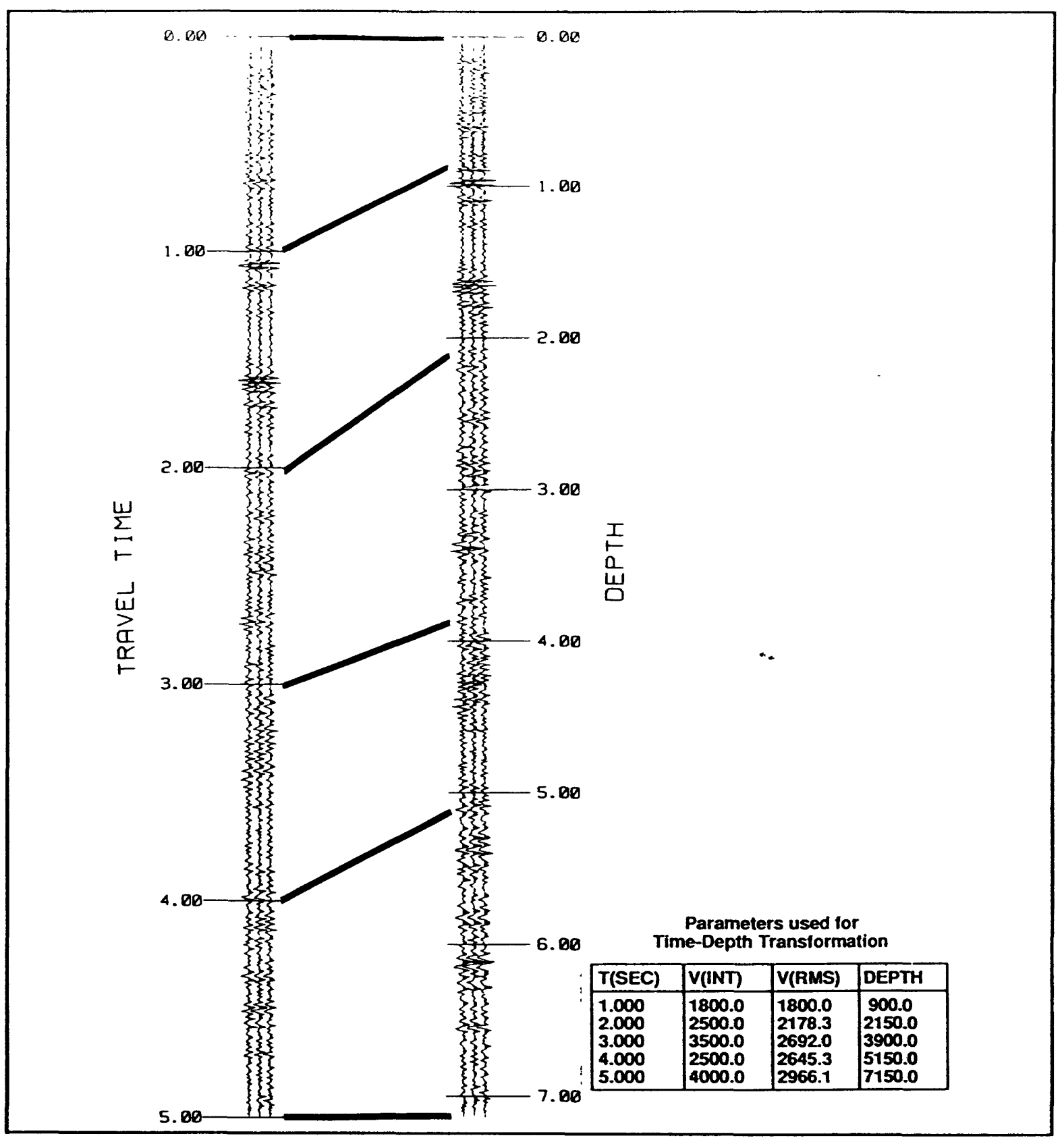

Figure 2. Two sets of the same three adjacent stacked seismic traces. Left set has TWTT as the vertcal axis; right set has Depth as the vertical axis. The Velocities used for the time-depth transformation are shown at the lower right.

Figure 3 is a digitized interpretation of a time-migrated seismic section. The horizons in the section have considerable dip and different velocities have been assigned to most of the layers. A thin, low velocity layer is truncated against horizon 2 (location 40, 2.5s). Consider the reflectors beneath surface location 20 . Figure 4 shows one image ray traced vertically downward from location 20 and deflected by Snell's law of refraction at each horizon. Figuse 5 is a display of the image rays traced at each odd-numbered surface location of Figure 3. Note that the image rays have not been deflected by horizons 6-8 because there is no velocity contrast across these horizons. Figure 6 is a display of these horizons from Figure 3 after conversion to depth by the image rays shown in Figure 5. Figure 6 is a display of the same

7 
horizons converted to depth by means of the vertical stretching method. Closeups of portions of Figures 6 and 7 are shown in Figures $8 \mathrm{a}$ and $8 \mathrm{~b}$, respectively. This figure illustrates that the position where horizon 3 pinches out against horizon 2 differs laterally by $218 \mathrm{~m}$ and vertically by $10 \mathrm{~m}$, depending on the method of depth conversion used.

Larner, et al (1981) give a comprehensive discussion of the use of image rays for depth conversion of migrated time sections.

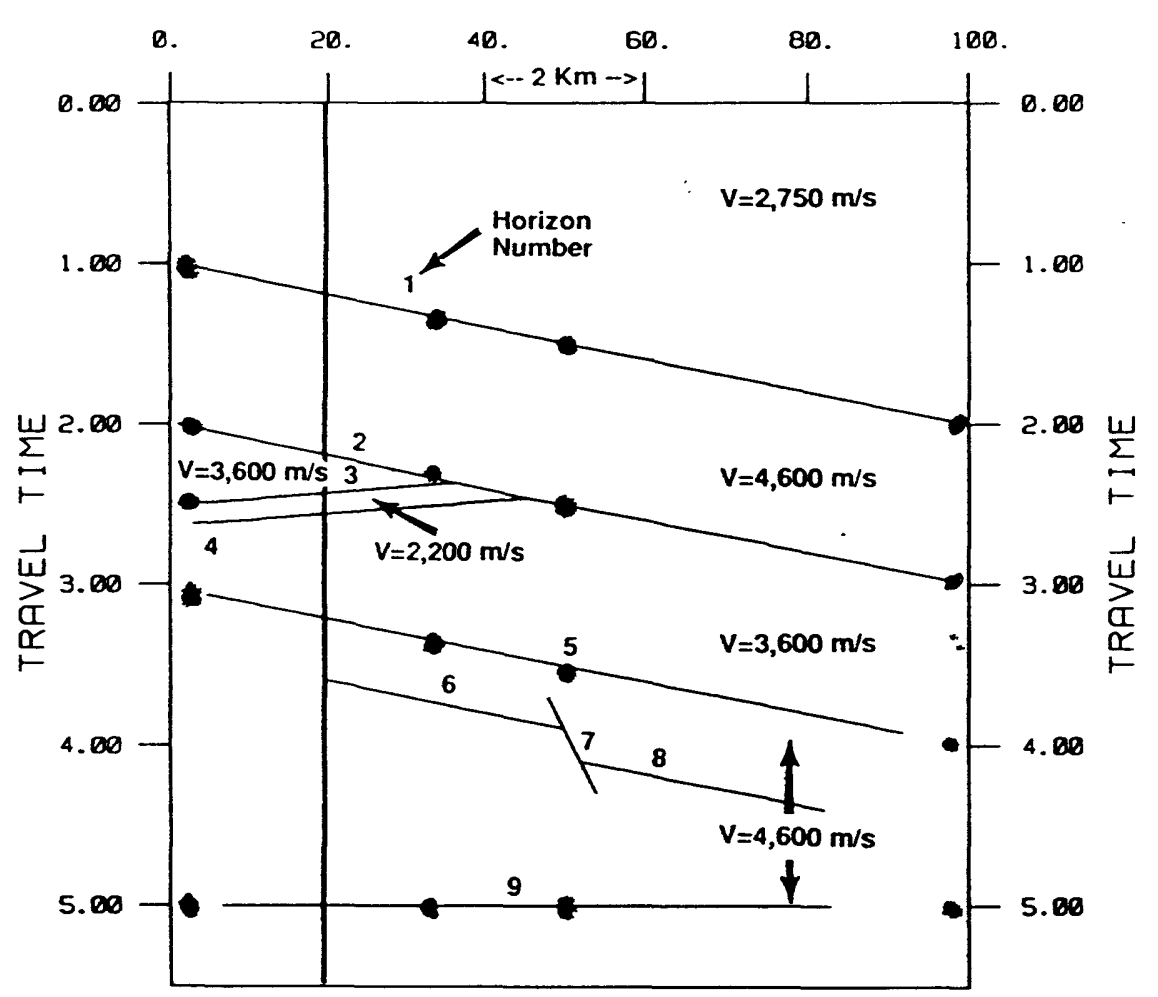

Figure 3. Line drawing interpretation, digitized using program SECDIG and displayed using program PLOTSEC. Interval velocities of the layers are annotated. Horizons are numbered for reference. Dots indicate points at which RMS velocities were calculated. 


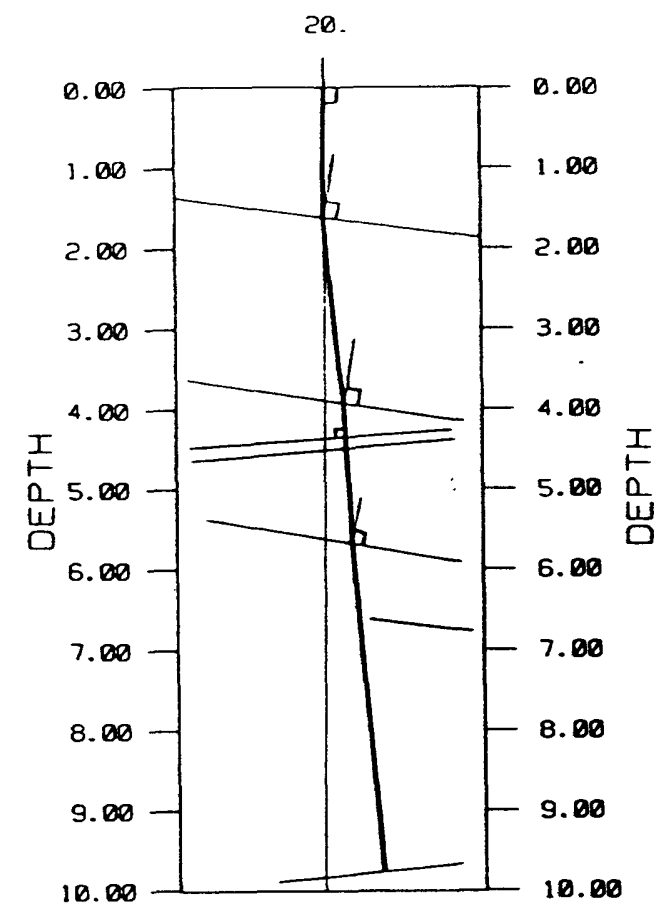

Figure 4. One image ray, traced downward from location 20 (Figure 3) using interval velocities as annotated on Figure 3. The ray is deflected laterally, based on Snell's law of refraction.

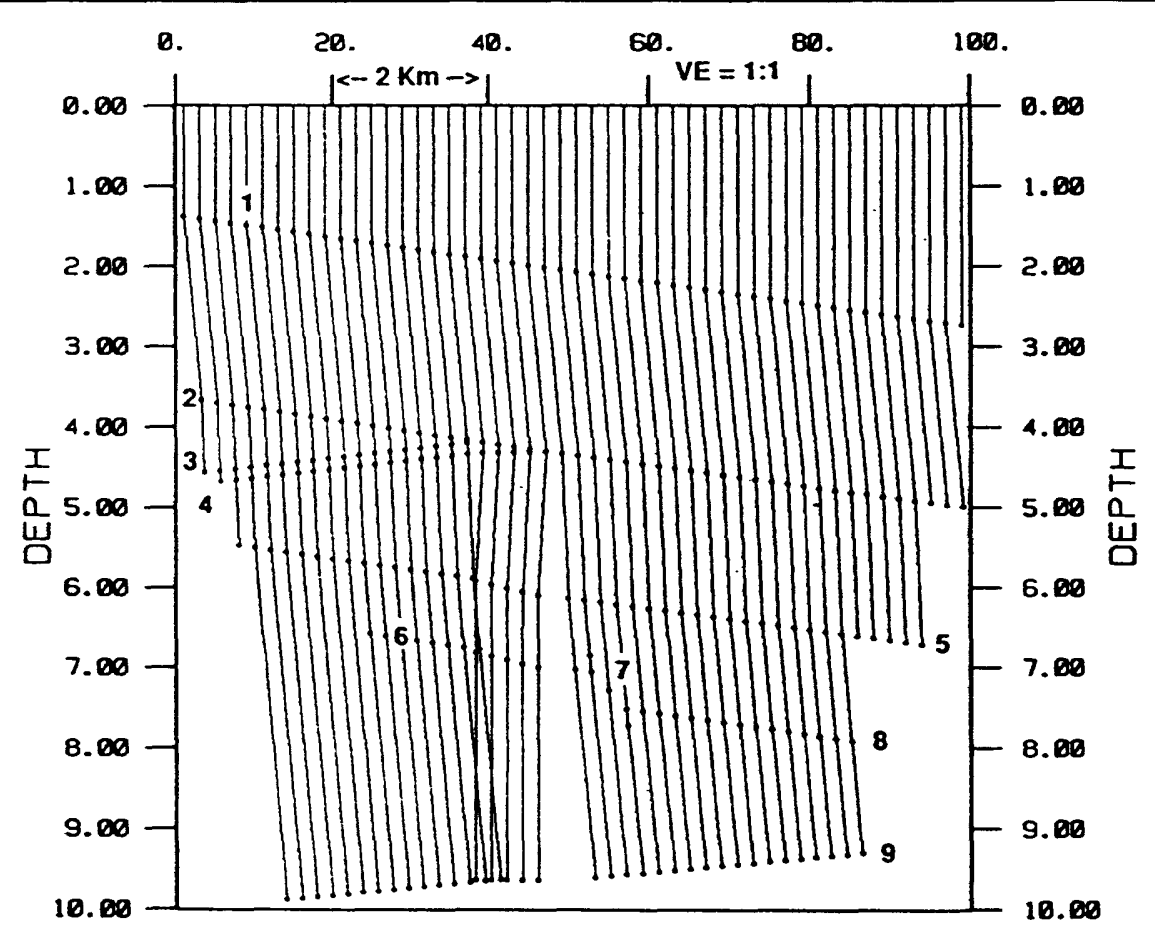

Figure 5. Image rays traced at odd-numbered surface locations. The input horizons and velocities are those shown in Figure 3. Circles are drawn whenever a ray encountered a horizon. Note that no ray bending occurs at horizons 6-8 because the interval velocity on either side of these layers are constant. 


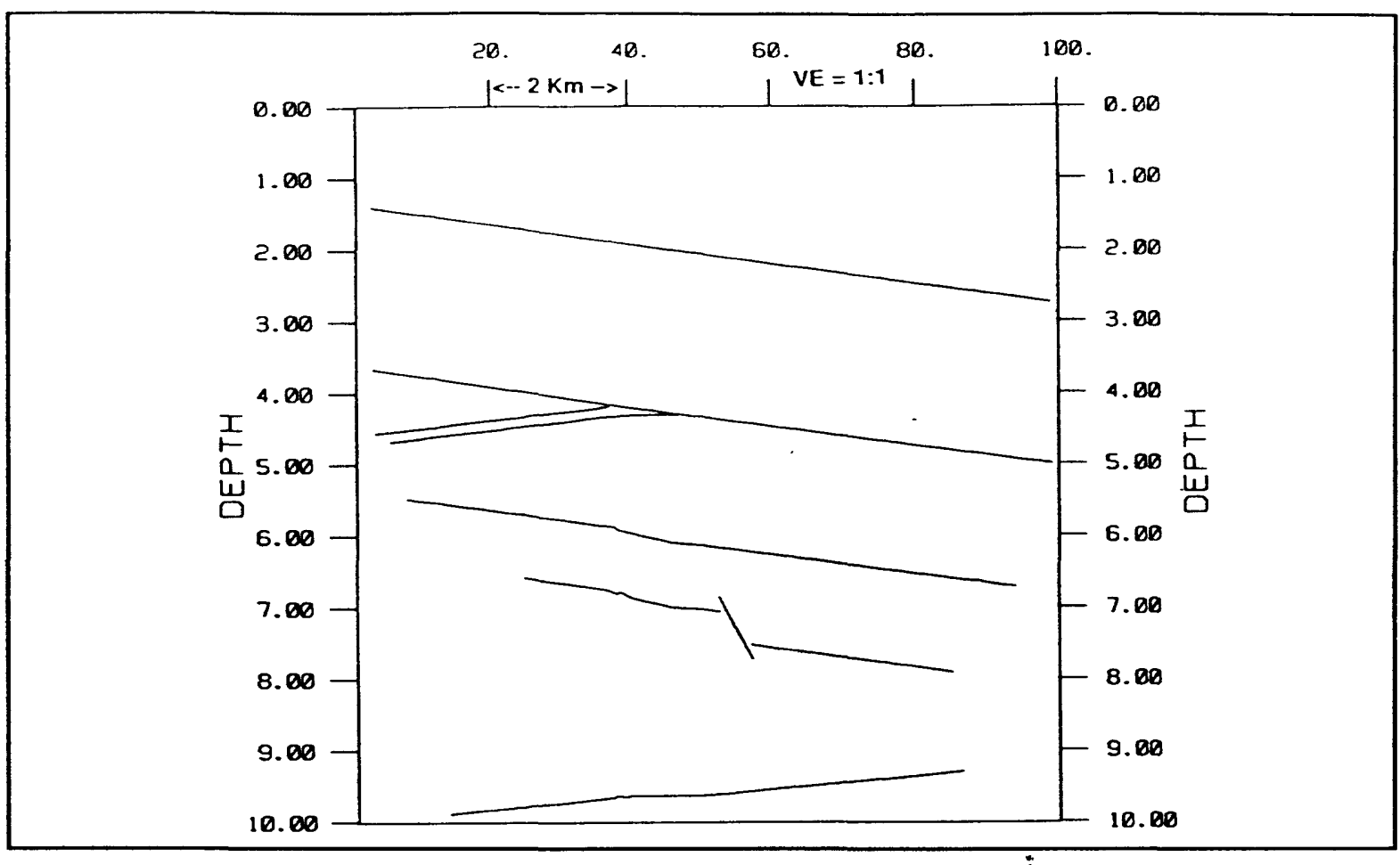

Figure 6. Depth section created from ray tracing shown in Figure 5.

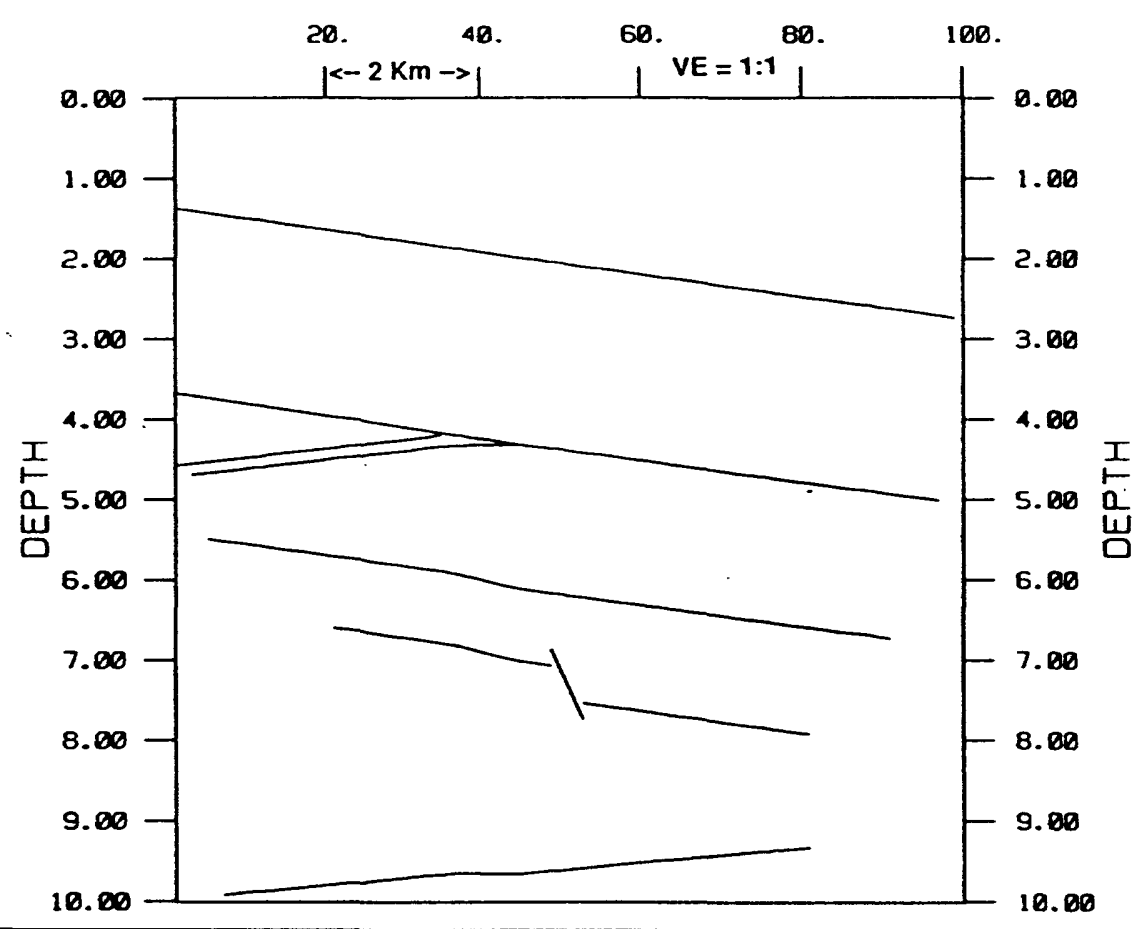

Figure 7. Depth section created by vertical stretching of the horizons from Figure 3, using interval velocities annotated on the Figure. 

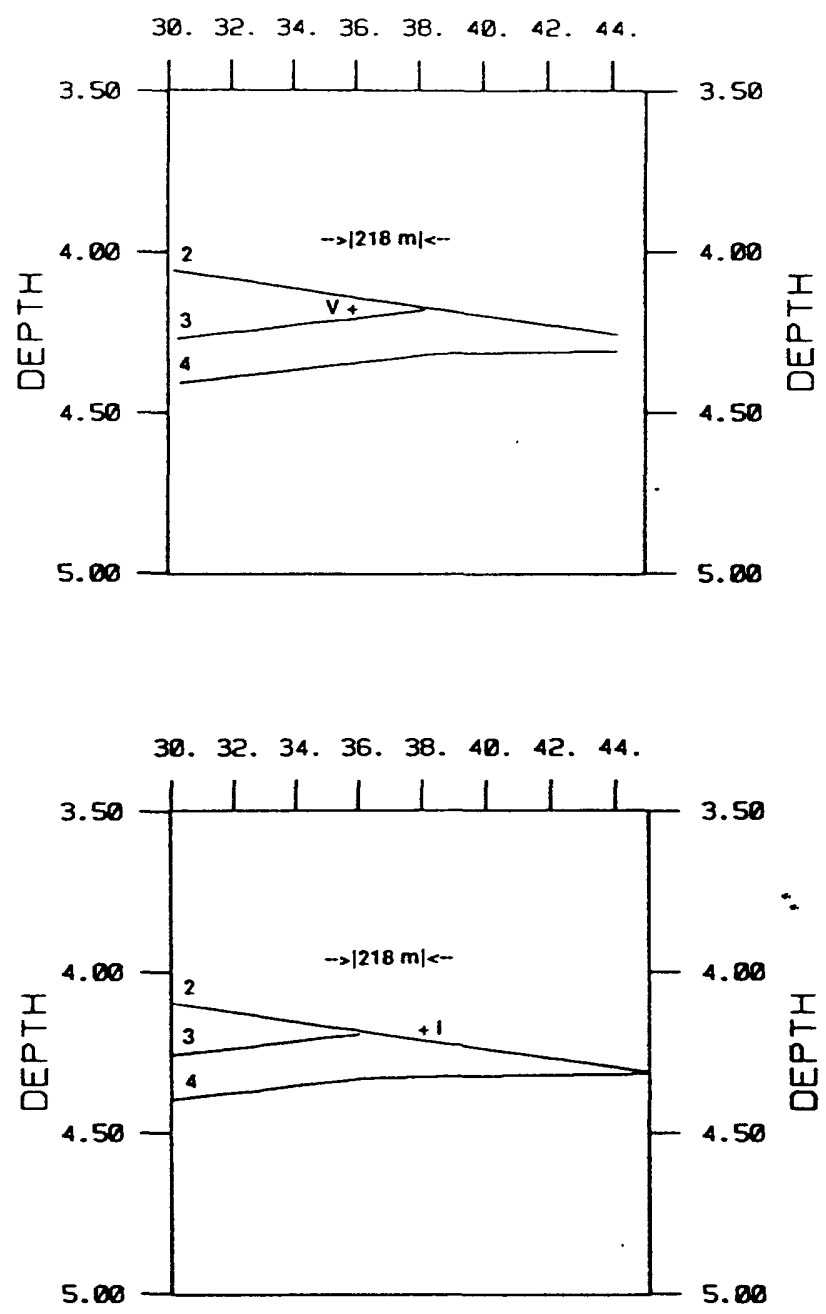

Figure 8. a. Top: Portion of Figure 6 (image ray depth section) at expanded scale. The cross $(+)$ labeled $\mathrm{V}$ indicates the position of the intersection of layers 2 and 3 if vertical stretching was used for depth conversion.

b. Bottom: Portion of Figure 7 (vertical stretching depth section) at expanded scale. The cross ( + ) labeled $I$ indicates the position of the intersection of layers 2 and 3 if image ray-tracing was used for depth conversion. 


\section{PROGRAM NAMES, FUNCTION, AND COMPATIBILITY}

A summary of the each program's name, and function, and computer availability is contained in table 1 (a detailed description is given later). A typical sequence of steps needed to convert a seismic section to depth using these programs is given in table 2. For most of the programs, a short overview is displayed on the screen; for all of the programs, the user is prompted for necessary parameters. When possible, a minimum, maximum, and default value is provided for each parameter.

Table 1. Summary of Program Name, Function, and Computer Availability.

\begin{tabular}{|l|l|}
\hline \multicolumn{1}{|c|}{ NAME } & \\
\hline $\begin{array}{l}\text { VELPACK } \\
\text { VAX and PC }\end{array}$ & User-interface program that provides access to all programs via menu-selection. \\
\hline $\begin{array}{l}\text { VELMOD } \\
\text { VAX and PC }\end{array}$ & Changes velocities by a user-specified percent. \\
\hline $\begin{array}{l}\text { VSMOOTH } \\
\text { VAX and PC }\end{array}$ & Smooths velocities by means of a weighted average technique. \\
\hline $\begin{array}{l}\text { ISOEDIT } \\
\text { PC only }\end{array}$ & $\begin{array}{l}\text { Interactively edit time-velocity functions on the CRT screen in isovelocity form or in T vs. } \\
\text { V form. Can also be used to obtain a display of isovelocity contours for quality control. }\end{array}$ \\
\hline $\begin{array}{l}\text { VUNITS } \\
\text { VAX and PC }\end{array}$ & Changes velocity units from FU/sec to M/sec or the reverse. \\
\hline $\begin{array}{l}\text { VCONVERT } \\
\text { VAX and PC }\end{array}$ & Converts RMS to INTERVAL velocity or the reverse. \\
\hline $\begin{array}{l}\text { VCONTOUR } \\
\text { VAX and PC }\end{array}$ & $\begin{array}{l}\text { Converts RMS to INTERVAL velocity (if necessary) and changes travel times to the mid- } \\
\text { point of the interval (for contouring). }\end{array}$ \\
\hline $\begin{array}{l}\text { TV2PC } \\
\text { VAX only }\end{array}$ & $\begin{array}{l}\text { Extracts velocities from the Seisdata database and writes a file in PC-format for use on the } \\
\text { PC (complement to HANDVEL). }\end{array}$ \\
\hline $\begin{array}{l}\text { HANDVEL } \\
\text { PC only }\end{array}$ & $\begin{array}{l}\text { Converts a velocity file from PC-format into a file having DISCO's *CALL DEFINE for- } \\
\text { mat for use by DISCO programs (complement to TV2PC). }\end{array}$ \\
\hline $\begin{array}{l}\text { SECDIG } \\
\text { VAX and PC }\end{array}$ & Digitize a line-drawing interpretation using Summagraphics digitizer. \\
\hline $\begin{array}{l}\text { PLOTSEC } \\
\text { VAX and PC }\end{array}$ & $\begin{array}{l}\text { Display digitized horizons in time or depth, or image rays (depth only) on the plotter or } \\
\text { CRT. }\end{array}$ \\
\hline $\begin{array}{l}\text { DEPTHRAY } \\
\text { VAX and PC }\end{array}$ & Convert Time section to Depth using vertical or image ray-tracing. \\
\hline $\begin{array}{l}\text { CFILES } \\
\text { VAX and PC }\end{array}$ & Combine separate files containing digitized time or depth sections. \\
\hline $\begin{array}{l}\text { REFORMAT } \\
\text { VAX and PC }\end{array}$ & Convert pre-V1.2 digitized sections to version 1.2 format. \\
\hline
\end{tabular}

As indicated in the previous table, most of the programs run on both the VAX and IBMcompatible PC's, some run exclusively on either the VAX or the PC, and some are complementary (HANDVEL vs. TV2PC).

Output files are $100 \%$ compatible between the PC and the VAX. Standard file transfer protocol, like KERMIT, can be used to up- and down-load files between computers. The format of the various files are given in the appendix. 
Some examples are as follows:

1. A digitized line-drawing interpretation can be displayed by PLOTSEC on either the VAX or the PC without modification to the file that contains the data.

2. A Velocity model, extracted from the Seisdata Database on the VAX, into a PC-format file can be used directly by program DEPTHRAY on the PC.

3. A file containing DISCO *CALL DEFINE style card images, created by HANDVEL on the PC, can be included in a DISCO job on the VAX and stored in the Seisdata Database for use by other DISCO processing modules.

The VAX programs that require a velocity model have the capability to access both the "old" (pre-DISCO 7.x) or "new" (DISCO 7.x and above) versions of the SEISDATA database.

Table 2. Sequence of steps used to create a seismic depth section. Two scenarios are described:

a. The data are processed on a DISCO system that contains this program package and the depth conversion is performed on a PC that is connected to the processing system, and

b. Only the processed record section is available and all steps are performed on a PC.

\begin{tabular}{|c|c|c|}
\hline STEP & FUNCTION PERFORMED & PROGRAM(S) USED \\
\hline \multirow[t]{2}{*}{1.} & a. Process seismic data to point of time-migrated stack. & $\begin{array}{l}\text { a. DISCO seismic data pro- } \\
\text { cessing software. }\end{array}$ \\
\hline & b. Obtain processed record section. & \\
\hline \multirow[t]{2}{*}{2.} & $\begin{array}{l}\text { a. Extract velocities used in processing from DISCO database and down- } \\
\text { load PC-format file to PC. }\end{array}$ & TV2PC \\
\hline & $\begin{array}{l}\text { b. Create a PC-format velocity file from velocities annotated on top of } \\
\text { record section. }\end{array}$ & $\begin{array}{l}\text { Text editor or word proces- } \\
\text { sor that can output ASCII } \\
\text { file. }\end{array}$ \\
\hline 3. & $\begin{array}{l}\text { (Optional): Convert RMS velocities to Interval velocities. Study result, } \\
\text { modify velocities if necessary, and assign interval velocities to layers. }\end{array}$ & $\begin{array}{l}\text { VCONVERT, ISOEDIT, } \\
\text { VCONTOUR, VSMOOTH, } \\
\text { VELMOD }\end{array}$ \\
\hline 4. & $\begin{array}{l}\text { Digitize line-drawing interpretation from features of interest. If step } 3 \\
\text { was performed, provide interval velocity above each horizon. }\end{array}$ & SECDIG \\
\hline 5. & Display digitized section for quality control. & PLOTSEC \\
\hline 6. & $\begin{array}{l}\text { Create Depth section using vertical and/or image ray tracing, using } \\
\text { appropriate velocity model(s). }\end{array}$ & DEPTHRAY \\
\hline 7. & Display depth conversion for quality control. If acceptable, go to step 9. & PLOTSEC \\
\hline 8. & Modify velocities; return to step 6. & $\begin{array}{l}\text { ISOEDIT, VELMOD, } \\
\text { VSMOOTH }\end{array}$ \\
\hline \multirow[t]{3}{*}{9.} & $\begin{array}{l}\text { a. Upload file containing depth converted horizons. Display final sec- } \\
\text { tion on Versatec plotter. }\end{array}$ & PLOTSEC \\
\hline & $\begin{array}{l}\text { a. Optionally, create DISCO velocity file of final velocities and upload } \\
\text { for further use by DISCO. }\end{array}$ & HANDVEL \\
\hline & $\begin{array}{l}\text { b. Display section at appropriate scale; use graphic dump program (not } \\
\text { provided) for hardcopy. }\end{array}$ & PLOTSEC \\
\hline
\end{tabular}




\section{INVOKING THE PROGRAMS}

\section{Menu Control}

On both the VAX and the PC, the individual programs can be accessed by means of a menu. The menu is a convenient way to run any of the programs without having to remember their names and is invoked by typing VELPACK at either the VMS prompt on the VAX or the DOS prompt on the PC. On the Geophysics Group's VAX, in Denver, the symbol VELPACK is defined automatically when you log in. Thus, typing this command at any time will provide access to the menu and the programs. Refer to the section later in this document for PC installation instructions.

The VAX menu appears as a numbered list of the programs available with a short explanation of the program displayed to the right of the program name (Figure 9). To run a program listed on this menu, type the corresponding number, or the program name, and press the ENTER or the RETURN key. That program will be executed; upon completion, the menu will be re-displayed and you can select another program. To end menu control, select item 1 (default) or type the word exit, or quit.

\section{Depth conversion and Velocity Modification Package, Version 1.2}

To run a program listed in the menu below, type the corresponding number or the program name and press the ENTER or the RETURN key ...

1. EXIT; End Menu control and return to VMS Command prompt.

2. SECDIG; Digitize a line-drawing interpretation using Summagraphics digitizer

3. PLOTSEC; Display digitized horizons (in time or depth), or Image rays

4. VSMOOTH; Smooth a velocity model by menas of a weighted average

5. VUNITS; Change velocity model units from $\mathrm{m} / \mathrm{s}$ to $\mathrm{ft} / \mathrm{s}$, or vice-versa

6. VELMOD; Modify velocity values by a user-specified percent

7. VCONVERT; Convert velocities from RMS to INTERVAL velocity, or vice-versa

8. VCONTOUR; Change travel time of INTERVAL velocities to midpoint of interval

9. TV2PC; Create a 'PC'-format velocity file from one in the DISCO database

10. CFILES; Combine separate files containing digitized time or depth sections

11. REFORMAT; Convert pre-V1.2 digitized sections to version 1.2 format

12. DEPTHRAY; Convert Time section to Depth using Vertical or Image Ray-Tracing

Type the menu-number or program-name [ 1 (EXIT) ]-->

Figure 9. VAX Menu Screen for program VELPACK. A program is chosen by either typing its name or corresponding number, then pressing the ENTER or RETURN key.

The PC menu appears as a list of the programs available, with one of the menu items highlighted (Figure 10). To run a program, press the up or down arrows to highlight a menu-item. As the highlighted items change, the program's name and function will be displayed near the bottom of the screen. When the desired menu-item is highlighted, press the ENTER or the right-arrow key. That program will be executed; upon completion, the menu will be re-displayed and you can select another program. To end menu control, press the Escape key (ESC), then press $\mathrm{Y}$ to confirm this selection. 
Depth conversion and Velocity modification package, Version 1.3

Select the program that you wish to run from the menu below ...

\begin{tabular}{|l}
\hline Digitize Section (Line-Drawing) \\
Display Digitized Section \\
Change Velocities (graphically) \\
Change Velocities (by \%) \\
\hline Smooth Vetocities \\
\hline Change Velocity Units \\
Change RMS to Interval (or Reverse) \\
Change Travel Times (for Contouring) \\
Write Handvel Cards \\
Combine Sections \\
Reformat X-T or X-Z \\
Convert Time to Depth
\end{tabular}

VSMOOTH; Smooth Velocities by a weighted average technique

4`: Highlight selection ENTER or $\rightarrow:$ Select ESC or $\leftarrow:$ End Program F1: Help F2: GoToDos

Figure 10. PC Menu Screen for program VELPACK. A program is chosen by pressing the up or down arrows to highlight the choice, then pressing ENTER or the right arrow to make the selection. Program VSMOOTH is highlighted.

\section{Executing the Programs Separately}

The VAX programs reside in the DCIEXE directory on the system disk. To invoke any program, type the following at the VMS prompt (usually a dollar sign, \$):

\section{\$ RUN DCI_EXE:PROGRAM-NAME}

To invoke any program on the PC, type its name at the DOS prompt (usually a right angle bracket, $>$ ). The program's executable file must reside in either the current directory, or in a directory that is a part of the computer's "path". 


\section{USERS' GUIDE TO THE PROGRAMS}

For all of the programs described below, input and output requirements are as follows, unless otherwise noted:

input: VAX program:

PC program:

output: $\quad$ VAX program:

PC program:
Velocity model in SEISDATA database. It is identified by means of DISCO's Project-Line-Name identification system.

File containing velocity model in PC-format.

File containing modified velocity model in DISCO module *CALL DEFINE (HANDVEL) style card images.

File containing modified velocity model in PC-format.

Furthermore, the user is required to type parameter values in response to screen prompts. Where possible, a minimum, maximum and default value will be provided for each of the parameters. To accept the default value, press the ENTER or RETURN key. Otherwise, type the new value and then press the ENTER or RETURN key. When all of the necessary parameters have been provided, the program's function will be performed (e.g. conversion of velocity values from RMS to interval velocity). Upon completion, the program will return to the initial prompt. The new default values will now be those used in the previous run of the program. This system of defaults allows the user to easily change one parameter, while keeping all of the other parameters unchanged. To end each program, type EXIT or QUIT at any prompt.

For programs DEPTHRAY and PLOTSEC, the following additional features are added to the system of providing parameters:

For the VAX: The user must first supply a valid input file name (one that uses legal characters, and exists in the specified directory). The program will then display a list of the default values for all of the other parameters on the screen. If these values are acceptable, the user can type the word SAME and the program's function will be performed using the parameters listed. Otherwise, the user can respond to each prompt individually, as described above, and then type SAME at the prompt following the last necessary change.

For the PC: The screen will be filled with a series of text "requestors" and menus (see Figure 11 for DEPTHRAY's parameter selection screen). Initially, the requestor for the path to the input file will be highlighted. The following editing rules apply:

1. To accept the parameter contained in a requestor, press either the Up arrow, Down arrow or the ENTER key.

2. To replace a parameter contained in a requestor, begin typing and the parameter in the requestor will be cleared.

3. To change (edit) a parameter contained in a requestor, use the left arrow, right arrow, END, or HOME keys to position the cursor. The Backspace and Delete keys will remove characters to the left and beneath the cursor, respectively. Characters typed will be inserted to the left of the cursor.

4. To recover the default response in a requestor, erase all of the characters in the requestor by means of the delete and/or backspace keys, then press the Up arrow, Down arrow or ENTER key.

5. To change a value in one of the menus, use the Up and Down arrows to highlight the desired item, then press the right arrow, left arrow, or ENTER key to accept the item.

To accept all the parameters and begin the program's function, press the insert (INS) key. To end the program, press the Escape (ESC) key, then press Y to confirm. 


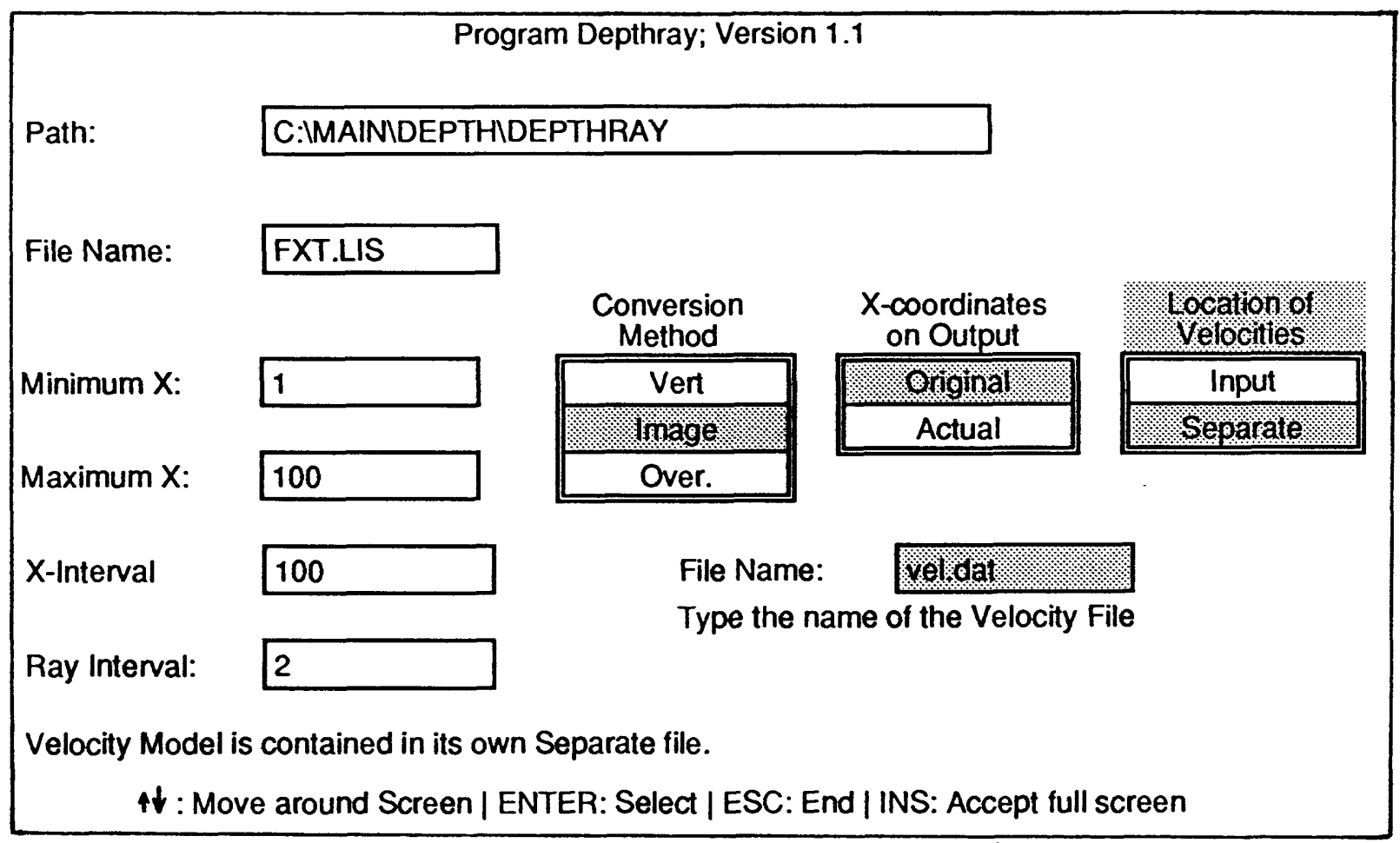

Figure 11. Parameter selection screen for program DEPTHRAY. Parameters shown are those used to create the depth section shown in Figures 12 and 13.

All of the programs have error-recovery procedures in the event that the user supplies an invalid parameter, like a file name that does not exist, or a scale factor that would cause a display to exceed the size of the plotting surface.

\section{ISOEDIT}

Program to interactively edit time-velocity functions on the CRT screen in isovelocity line form or in T vs. V form. A Users' guide and complete documentation is given in Zihlman (1989). The isovelocity contour feature of this program can be used by itself to obtain quality control displays of velocity models after the velocities have been modified by other programs (VELMOD, VSMOOTH, VCONTOUR, VCONVERT).

Optional output: File containing modified time-velocity pairs in DISCO's *CALL DEFINE format.

Limitations: $\quad$ Available on the PC only because of need for on-screen graphics.

\section{HANDVEL}

Converts a velocity file from PC-format into a file having DISCO's *CALL DEFINE format. The user is prompted for the input and output file names. This program is the complement to program TV2PC.

Limitations: $\quad$ Available on the VAX only.

TV2PC

Converts a velocity model from the SEISDATA database into a velocity file in PC-format. The user is prompted for the input velocity name and output file name. This program is the complement to program HANDVEL.

Limitations: $\quad$ Available on PC only. 


\section{VCONTOUR}

Changes the travel time of each time-velocity pair to the midpoint of the interval (usually used only for isovelocity contouring purposes). The user is prompted for the input velocity file (or name), output file name, whether the input velocities are in either RMS or INTERVAL velocity, and whether the user wishes to leave the time of the first time-velocity pair of each function unchanged (useful for marine seismic data where the first time-velocity pair is that of the seafloor). RMS velocities will be converted to INTERVAL velocity, if necessary, by means of Dix's formula (1955).

\section{VELMOD}

Changes the velocity values in a velocity model by a user-specified percentage. The user is prompted for the input velocity file (or name), output file name, whether the input velocities are in either RMS or INTERVAL velocity, and whether the user wishes to leave the first time-velocity pair of each function unchanged (useful for marine seismic data where the first time-velocity pair is that of the seafloor).

\section{VSMOOTH}

Smooths velocities by means of a weighted average technique. Velocity functions are recalculated at a regular, user-specified, spatial sampling interval. At each new spatial sampling point (X-coordinate), those velocity functions that fall within a user-specified range of $X$ about that point are averaged together. The user can specify a linear weighting taper so that velocities averaged together are weighted based on their distance from the new function's location. There is an option to smooth along lines of constant time or along geologic structure.

Optional input: File containing X-time pairs that define the geologic structure along which to smooth.

\section{VCONVERT}

Converts RMS velocities to INTERVAL velocities and vice-versa, by means of Dix's formula (1955). The user is prompted for the input velocity file (or name) and output file name.

Optional output: File containing a table of: Travel-time, RMS-Velocity, INTERVALVelocity, and Depth for each time-velocity pair.

\section{VUNITS}

Converts velocity units from meters/sec to feet/sec or vice-versa. The user is prompted for the input velocity file (or name) and the output file name.

\section{DEPTHRAY}

Convert Time section to Depth using vertical (stretching) or image ray-tracing. Rays are traced at a user-specified surface interval and all horizons encountered beneath each ray are converted to depth. Vertical ray tracing is the most common way to convert a time section to depth but image-rays should be used to accurately convert a time-migrated section to depth, especially in the presence of dip.

Input:

Optional Input:
File containing digitized horizons, in time, to be converted to depth. This file can contain interval velocities to be used for the depth conversion (entered during SECDIG).

RMS velocities contained in a PC-format velocity file or DISCO's seisdata database. 
Output:

1. CRT Display of rays traced (if PC has graphics capability).

2. (Optional) If VAX has rasterizer and VERSATEC plotter, pagesize display of rays traced and/or layers, in depth.

3. (Optional) User-named file containing Horizons, in depth.

4. (Optional) User-named file containing image rays traced.

Examples: Figure 3 is a line drawing interpretation that was created using program SECDIG and input to program DEPTHRAY. Figure 11 shows the parameter selection screen for the PC version of DEPTHRAY. With the exception of the name of the separate velocity file (VEL.DAT) the parameters shown on Figure 11 are those that were used to create the depth sections shown in Figures 5, 6, and 8a. The velocity model used for the previously shown depth sections is contained in file FXT.LIS (contained on the executables disk) and those velocity values are annotated on Figure 3.

An alternate way to provide velocities for depth conversion is to use an RMS velocity model contained in either a separate PC-format velocity file, or in the DISCO database. It is likely that RMS velocities will be available after processing; these velocities can be used directly, or can be modified using programs contained in this package. However, for this example, the RMS velocities were calculated at the points indicated by the large dots in Figure 3, using the interval velocities annotated on the figure. These values are stored in file VEL.DAT, contained on the executables disk.

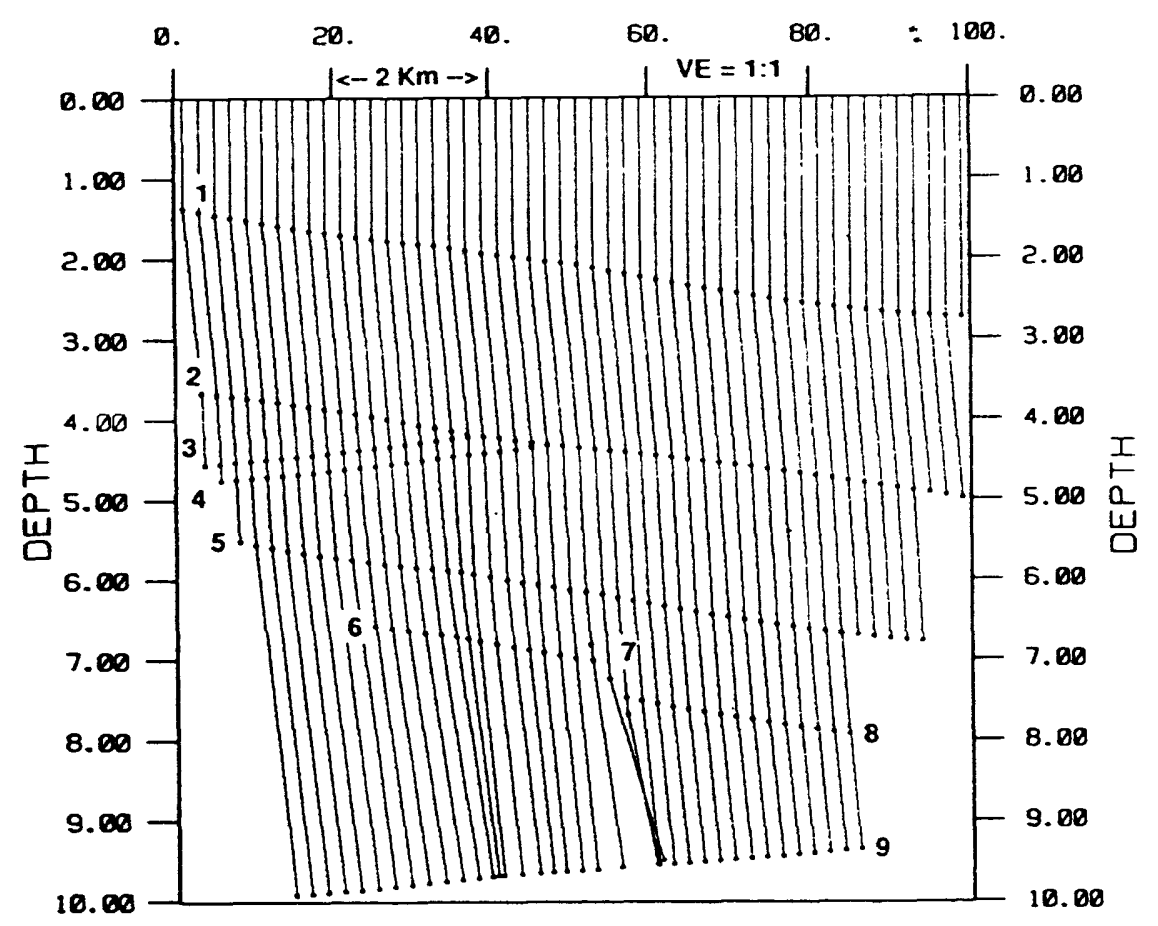

Figure 12. Image rays traced using horizons from Figure 3 and velocities contained in file VEL.DAT. Note ray bending at horizons $6-8$, in contrast to Figure 5. 
The result of the image ray tracing, using the velocities contained in file VEL.DAT, is shown in Figure 12 and the corresponding horizon display is shown in Figure 13. These results are different from those shown in Figures 5 and 6 . The reason for the differences is that when RMS velocities contained in a separate file are used, DEPTHRAY determines the interval velocity above and below a horizon by first determining an interpolated RMS velocity for the top and bottom of each layer, and then calculates the interval velocity. In this example, the interval velocities determined on either side of horizons 6-8 differ and thus the image rays are deflected at these horizons (especially so at horizon no. 7), in contrast to the image ray display shown in Figure 5. Furthermore, in some areas the interval velocities, calculated from the RMS velocities, do not change as abruptly as do the original interval velocities (Figure 3), and thus there is less ray bending. Note especially the rays near the truncation of the low velocity lense (Figures 5 and 7, locations 30-50, depth 4.0). The low velocity lense is also thicker in Figures 12 and 13 than in Figures 5 and 6 because with so few RMS velocity points defined, the low interval velocity of the lense is not resolved. For the same reason, some of the other layers have different thicknesses. A depth section created using vertical stretching and velocities from VEL.DAT is shown in Figure 14. Again, note the differences in the thickness of the layers between this section and that shown in Figure 7.

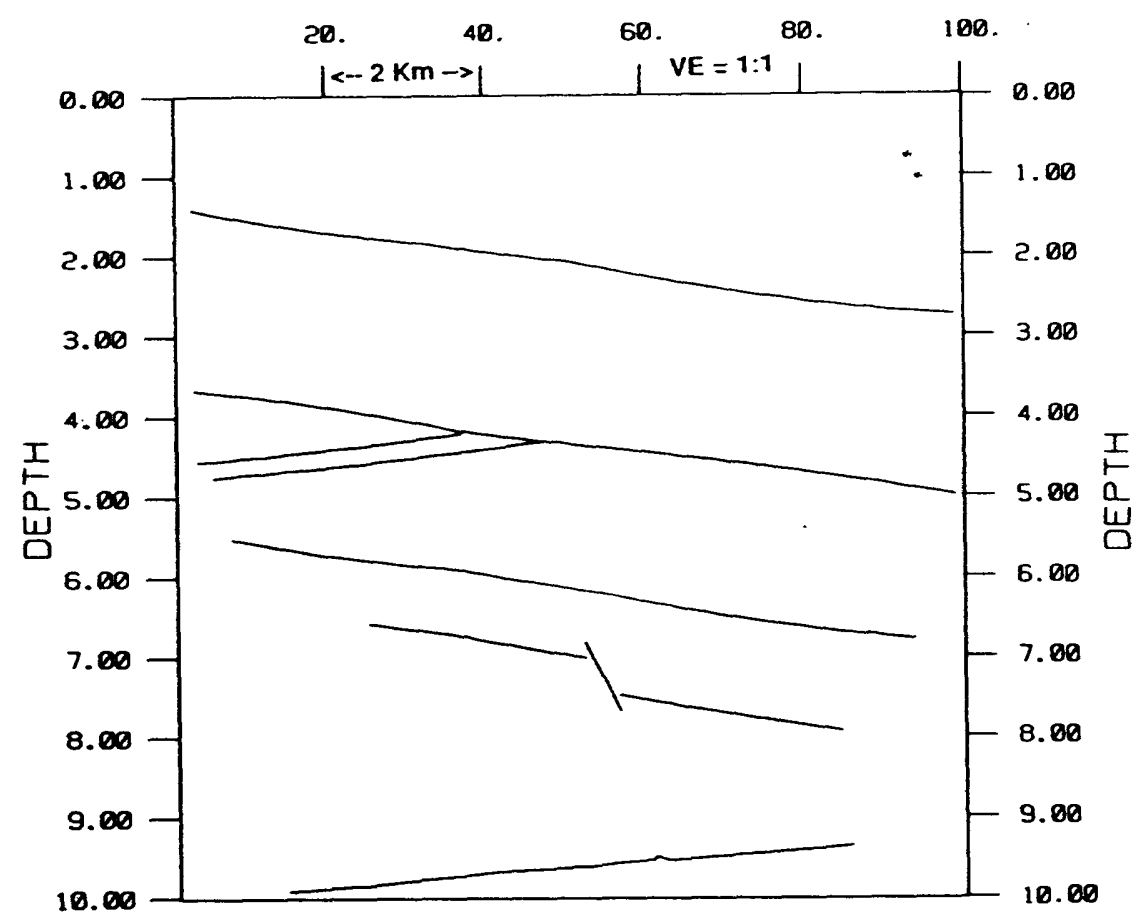

Figure 13. Depth section created from image rays shown in Figure 12. 


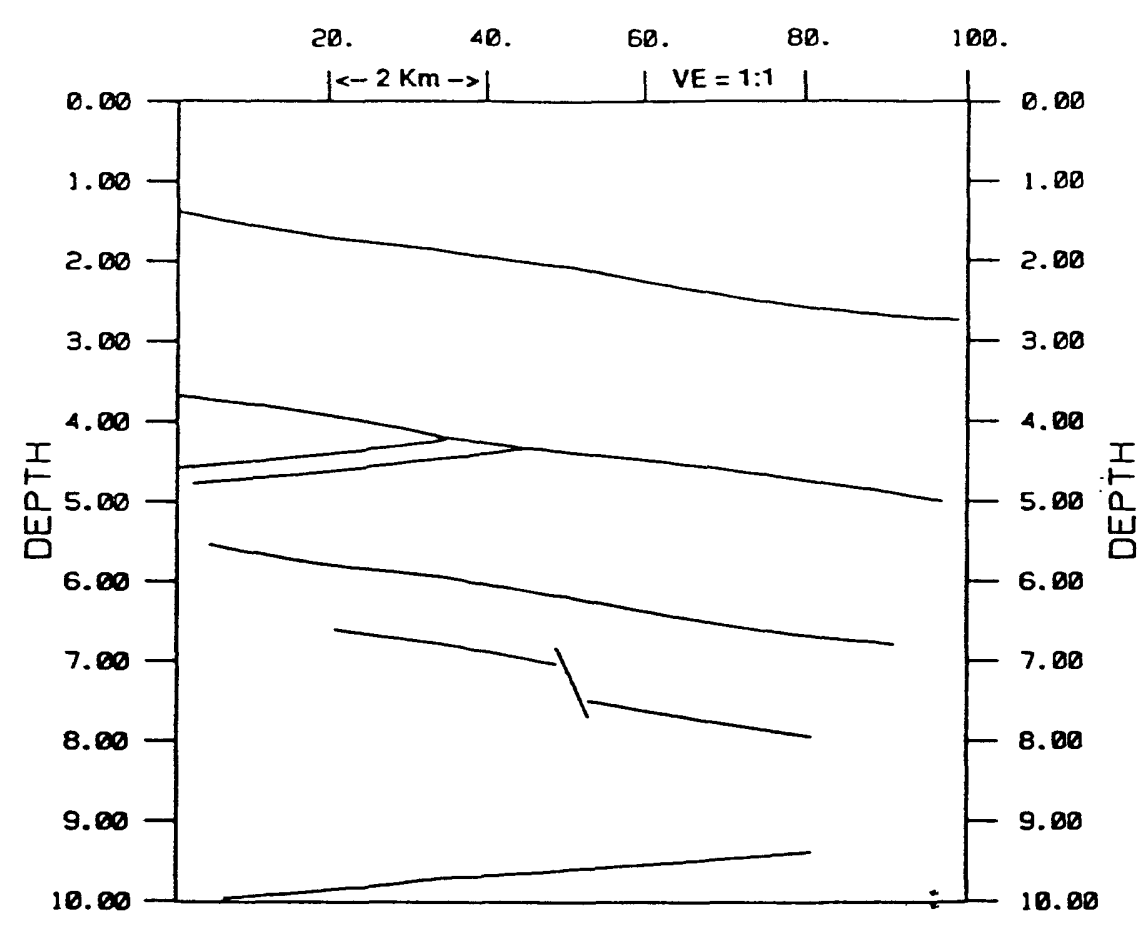

Figure 14. Depth section created from vertical stretching of horizons in Figure 3 and velocities contained in file VEL.DAT.

It is the responsibility of the interpreter to determine the correct velocity model to use for depth conversion.

\section{SECDIG}

Digitize a line-drawing interpretation using Summagraphics digitizer having either a 13-key or 4-key cursor pad. The user can digitize any number of horizons and also input the Interval Velocity of the layer directly above the horizon being digitized. The PC version requires that the digitizer be connected to COM Port \#1 by means of a NULL modem cable. The source code for this program can be modified to accept the input from other kinds of digitizers.

The line drawing interpretation shown in Figure 3 was created using SECDIG and is contained in file FXT.LIS on the executables disk.

\section{Input:}

Output:

\section{Summagraphics Digitizer.}

File containing digitized horizons suitable for input to the plotting program PLOTSEC, or depth-conversion program DEPTHRAY. The output format is standardized to conform to that used in other linedrawing programs. For an example, see "A PC Program for Migration of Seismic Reflection Profiles" (Unger, 1988) and the Appendix.

\section{PLOTSEC}

Display digitized horizons in time or depth, or image rays (depth only) on the plotter or CRT. The user can control the scales and annotation frequency in both the $X$ and $Y$ directions. $Y$ scales are defined in inches/second for time sections and vertical exaggeration for depth sections. The program will automatically detect whether a file contains horizons or image-rays. 
If rays, the program will assume a depth section. If horizons, the user will be prompted to indicate whether the horizons are in time or depth. Figures 3-8 and 12-14 were created using the VAX version of PLOTSEC.

Input: $\quad$ File containing digitized horizons, or image rays.

Output: $\quad$ Display on PC screen or VERSATEC plotter

\section{CFILES}

Combine separate files containing digitized time or depth sections. The global minima and maxima for both the $\mathrm{X}$ and $\mathrm{Y}$ coordinates will be determined from the input files and written to the header of the output file. The user is prompted for the input and output file names.

Input: At least two (2) files containing digitized horizons.

Output:

Single file containing all horizons

\section{REFORMAT}

Convert pre-V1.2 digitized sections to version 1.2 format. The user is prompted for the input and output file names. Versions prior to 1.2 were distributed informally and thus few users will need this program.

Input:

File containing digitized horizons in pre-Verison 1.2 format

Output:

File containing digitized horizons Verison 1.2 format

\section{ADDITIONAL HELP}

For program ISOEDIT, a complete user's guide, documentation and source code has been published separately by Zihlman (1989). If you do not have this publication, press F1 during program execution to get on-screen help information.

Most of the programs display an overview when they begin. Furthermore, when running PLOTSEC and DEPTHRAY on the PC, press F1 to get help on the current parameter being requested. See the next section for details on how to install the help utility on the PC.

On the VAX, all of the programs have been documented in the DISCO HELP utility. This help information applies to the PC programs as well. To access this utility, type HLPDSP at the VMS prompt. The help format is like the VMS help utility with the exception that is does not automatically stop printing when the screen is full; the user must stop the scrolling manually in order to read multiple pages. All of the modules are documented and can be accessed by name. Thus, to get help for VSMOOTH, type HLPDSP VSMOOTH.

\section{PC INSTALLATION}

The executable and help files for all of the PC programs reside on one disk. Copy ALL of the executable files (files with an extension of .EXE or .COM) to a directory in the computer's "path". To find which directories are in the path, type PATH at the MS-DOS prompt. To run an individual program, type its name. To run the menu program which gives access to all of the programs, type VELPACK.

If your computer has Hercules Graphics, the graphics support routines contained in file QBHERC.COM must be loaded prior to running PLOTSEC and DEPTHRAY (DEPTHRAY will run without graphics capability but such capability will be needed eventually to display the results). Type QBHERC at the MS-DOS prompt prior to running PLOTSEC or DEPTHRAY (or VELPACK, if PLOTSEC and/or DEPTHRAY will be run from the menu). This procedure needs to be performed only once each time the machine is booted; the graphics support routines 
will remain resident in the computer's memory until the machine is turned off, or rebooted. These routines take only 7 kilobytes of memory and thus should not significantly affect the performance of other programs.

In order to have access to the help files from program DEPTHRAY and PLOTSEC, a help directory must be created and the environment variable HLP must be set. The help directory can be any legal DOS directory. The following procedure explains how to install a help directory named HELP on hard drive C:

1. If the directory does not already exist, create one by typing:

\section{C:LHELP}

2. Copy files PLOTSEC.HLP and DEPTHRAY.HLP to that directory.

3. Create an environment variable, HLP, by adding the following line to the AUTOEXEC.BAT file:

\section{SET HLP = C: $\mid$ HELP|}

4. Execute the AUTOEXEC.BAT file by either pressing CTRL-ALT-DEL, or by turning the computer off, then on.

The above procedure permanently installs the help facility. Step 3 insures that the enviroment varialble HLP is defined each time that the machine is booted. After successful installation, anytime that key $\mathrm{F} 1$ is pressed during execution of programs PLOTSEC or DEPTHRAY, help information will appear in a window on the screen.

\section{APPENDIX}

\section{The Velocity Files Format}

On the PC, the file that contains a velocity model is referred to as a "PC-format" velocity file. This type of file is input to and output from the velocity modification programs and can also be used as optional input to the depth conversion program. It consists of a series of time-velocity pairs at different control points ( $x$-coordinates) along a seismic line and has the format:

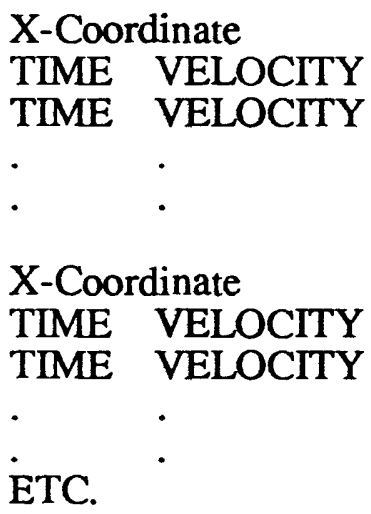

$$
\begin{aligned}
& <--1 \text { st line of file } \\
& <--2 \text { nd " " } \\
& <- \text { Blank line indicating end of function }
\end{aligned}
$$

File VEL.DAT, contained on the executables disk, is an example of this type of file.

On the VAX, a "PC-format" velocity file is output from program TV2PC. All other velocity modification programs on the VAX will output velocity files in a format suitable for input to DISCO's *CALL DEFINE module (on the PC, program HANDVEL will output a file in this format). 


\section{The Digitized Seismic Section Format}

The digitized line-drawing interpretation file is output by program SECDIG. Files having this format are input to, and output from, programs DEPTHRAY, CFILES, and REFORMAT.

The file has two header lines which contain the following information:

Line 1: minimum and maximum $X$ coordinates (CDP, Shotpoint, distance, etc.), minimum and maximum $Y$ coordinates (Time or Depth), default $Y$ coordinate annotation increment; and

Line 2: the default plot direction (left-right or right-left).

Following the two header lines, are lines which contain the digitized points (X-T or X-Z). The line that indicates the beginning of a digitized horizon can optionally contain the velocity of the medium immediately above the horizon, as the third item on the line. This velocity is input during program SECDIG.

Sample file FXT.LIS, contained on the executables disk, is an example of this type of file. Note that the time coordinate must be seconds and the depth coordinate must be in kilo-feet or kilometers; the $\mathrm{X}$ coordinate can be in any units.

Except for the two header lines, the format of a digitized time section output from program SECDIG is suitable for input to the PC migration program, by Unger (1988).

A portion of this type of file is shown below:

3580. 4280. 4000. 9000.1000.

$\mathrm{RL}$

10.2200.

0 3617. 5.533

$0 \quad 3630.5 .564$

- .

10.2500.

0 3764. 5.423

$0 \quad 3777 . \quad 5.518$

$\cdot \cdot \cdot$

-10.0 . 0.

\section{The Raypath File Format}

The DEPTHRAY output file that contains the rays traced has a different format from that of the file that contains digitized layers.

The two header lines are very similar to those of the layer file, except that the 2nd header line contains the word RAYS, which identifies this file as a RAYPATH file.

The line that indicates the beginning of each ray contains three items:

1) Number of horizons intersected by the ray

2) $X$ coordinate of the surface emergence point of the ray in the same units as the $\mathrm{X}$-coordinates of the header.

3) $X$ coordinate of the surface emergence point of the ray in actual distance units (meters, feet, etc). This value is determined during program DEPTHRAY, based on the usersupplied parameters. 
Other lines contain the $\mathrm{X}, \mathrm{Z}, \mathrm{T}$ coordinates of the inflection points of the ray. A portion of this type of file is shown below:

$\begin{array}{llll}\begin{array}{l}1 \quad 98 \text { 0 } 9852.959 \\ \text { LR,RAYS }\end{array} & 1000 & & \begin{array}{l}\text { <-- 1st Header line } \\ \text { <-- 2nd Header line }\end{array} \\ 3 & 1 & 100 & \text { <-- Indicates beginning of ray } \\ 1.000 & 1.375 & 1.223 & \text { <-- Inflection point of ray (X, Z and T) } \\ 3.163 & 3.664 & 2.575 & \text { <-- Inflection point of ray (X, Z and T) } \\ 3.546 & 4.563 & 4.113 & \text { <-- Ending point of ray (X, Z and T) } \\ 5 & 6 & 600 & \text { <-- Indicates beginning of next ray } \\ 6.000 & 1.444 & 1.421 & \text { <-- Inflection point of ray (X, Z and T) } \\ 8.166 & 3.737 & 2.356 & \\ 8.495 & 4.509 & 4.322 & \end{array}$

\section{REFERENCES}

Claerbout, J., 1976, Fundamentals of geophysical data processing; New York, McGraw-Hill Book Co., Inc, 247p.

Claerbout, J., and Doherty, S., 1972, Downward continuation of moveout-corrected seismograms, Geophysics, v. 37, p. 741-768.

Dix, C.H., 1955, Seismic Velocities from Surface Measurements, Geophysics, v. 20, p. 68-86

Hubral, P., 1977, Time Migration - some ray theoretical aspects, Geophysical Prospecting, v. 25, p. $738-745$

Larner, Kenneth L., Hatton, L., Gibson, B.S., And Hsu, I, 1981, Depth migration of imaged time sections, Geophysics, v. 46, no. 5, p. 734-750

Sheriff, R.E., 1976, Encyclopedic dictionary of Exploration Geophysics, Society of Exploration Geophysicists, Tulsa, OK, $266 \mathrm{p}$.

Unger, John D., 1988, A PC program for migration of seismic reflection profiles, Geobyte, v. 3, no. 3, p.42-54

Zihlman, F.N., 1989, ISOEDIT, A Program for Interactive Editing of Seismic Reflection Velocity Models, U.S. Geological Survey Open-File Report 89-310A and B, 34p. 